\title{
Efficacy of the FIFA 11+ Injury Prevention Program in the Collegiate Male Soccer Player
}

\author{
Holly Silvers-Granelli, MPT ${ }^{\star}, \dagger, \ddagger, \S$, Bert Mandelbaum, MD ${ }^{\dagger}$, , Ola Adeniji, MS $^{\dagger}$, Stephanie \\ Insler, BA ${ }^{\dagger}$, Mario Bizzini, PT, PhD", Ryan Pohlig, PhD", Astrid Junge, PhD", Lynn Snyder- \\ Mackler, PT, ATC, ScD ${ }^{\ddagger}, \#$, and Jiri Dvorak, MD"
}

†Santa Monica Sports Medicine Foundation, Santa Monica, California, USA ‡Department of Biomechanical and Movement Sciences, University of Delaware, Newark, Delaware, USA §Institute for Sports Sciences, Los Angeles, California, USA "Fédération Internationale de Football Association (FIFA) Medical Assessment and Research Centre (F-MARC), Zurich, Switzerland IBiostatistics Core Facility, College of Health Sciences, University of Delaware, Newark, Delaware, USA \#Department of Physical Therapy and Biomechanics and Movement Science Program, University of Delaware, Newark, Delaware, USA

\begin{abstract}
Background-The Fédération Internationale de Football Association (FIFA) 11+ program has been shown to be an effective injury prevention program in the female soccer cohort, but there is a paucity of research to demonstrate its efficacy in the male population.
\end{abstract}

Hypothesis-To examine the efficacy of the FIFA 11+ program in men's collegiate United States National Collegiate Athletic Association (NCAA) Division I and Division II soccer.

Study Design—Randomized controlled trial; Level of evidence, 1.

Methods-Before the commencement of the fall 2012 season, every NCAA Division I and Division II men's collegiate soccer team $(\mathrm{N}=396)$ was solicited to participate in this research study. Human ethics review board approval was obtained through Quorum Review IRB. Sixty-five teams were randomized: 34 to the control group (CG; 850 players) and 31 to the intervention group (IG; 675 players). Four teams in the IG did not complete the study, reducing the number for analysis to 61 . The FIFA 11+ injury prevention program served as the intervention and was utilized weekly. Athlete-exposures (AEs), compliance, and injury data were recorded using a secure Internet-based system.

Results-In the CG, 665 injuries (mean \pm SD, $19.56 \pm 11.01$ ) were reported for 34 teams, which corresponded to an incidence rate (IR) of 15.04 injuries per 1000 AEs. In the IG, 285 injuries

For reprints and permission queries, please visit SAGE's Web site at http://www.sagepub.com/journalsPermissions.nav

*Address correspondence to Holly Silvers-Granelli, MPT, Santa Monica Sports Medicine Foundation, 11611 San Vicente Boulevard, GF-1, Los Angeles, CA 90049, USA (hollysilverspt@gmail.com).

This article is in partial fulfillment of the doctoral dissertation for H.S.-G. at the University of Delaware.

Presented at the 40th annual meeting of the AOSSM, Seattle, Washington, July 2014.

One or more of the authors has declared the following potential conflict of interest 
(mean $\pm \mathrm{SD}, 10.56 \pm 3.64$ ) were reported for 27 teams, which corresponded to an IR of 8.09 injuries per 1000 AEs. Total days missed because of injury were significantly higher for the CG (mean $\pm \mathrm{SD}, 13.20 \pm 26.6$ days) than for the $\mathrm{IG}$ (mean $\pm \mathrm{SD}, 10.08 \pm 14.68$ days) $(P=.007)$. There was no difference for time loss due to injury based on field type $(P=.341)$.

Conclusion-The FIFA $11+$ significantly reduced injury rates by $46.1 \%$ and decreased time loss to injury by $28.6 \%$ in the competitive male collegiate soccer player (rate ratio, 0.54 [95\% CI, $0.49-0.59$ ]; $P<.0001$ ) (number needed to treat $=2.64$ ).

\section{Keywords}

injury prevention; epidemiology; neuromuscular training; FIFA 11+

Soccer (football) is the most widely played sport among both men and women, with approximately 300 million registered players globally. ${ }^{10,20,25}$ The growth of the sport in the United States (US) has been unprecedented. It is currently the third most popularly played sport, with over 13 million Americans participating at the youth and adult levels. ${ }^{57}$ Major League Soccer (MLS) is currently in its 20th season and has grown to 20 professional teams within the US and in Canada since its inception, with further expansion on the horizon. ${ }^{42}$ In addition, there are approximately 412,000 high school male and 23,000 collegiate male soccer players participating in US National Collegiate Athletic Association (NCAA) soccer. ${ }^{46}$ The number of participants is increasing annually, imparting a multitude of positive effects with respect to emotional and physical wellness and health, and is influential in decreasing the onset of illness and systemic disease. However, the risks associated with soccer participation have been well documented. ${ }^{* *}$ In the past 2 decades, numerous attempts have been made to gain a fuller understanding about the mechanism of these injuries and how researchers can reduce the incidence of such injuries. ${ }^{\dagger \dagger}$

Soccer-related injuries are not uncommon. There have been numerous research studies published elucidating the incidence and prevalence of soccer-related injuries in both male and female players; recreational, amateur, and professional players; and youth and adult players. ${ }^{11,12,21,28,32,37,48}$ Researchers have also focused on variations in the injury rate occurring on artificial turf versus grass and during tournament play versus regular-season play. $7,22,24,36,48$ However, there is a growing body of evidence validating the notion that injury prevention programs have the inherent ability to decrease the incidence of soccerrelated injuries and the time loss associated with such injuries. ${ }^{31,49,52-55}$ In the past 2 decades, many injury prevention efforts were focused solely on female athletes, namely, on anterior cruciate ligament (ACL) injury prevention. ${ }^{24,29,30,33,40}$ Recent publications have focused on the injury mechanisms related to male soccer players, but most of the injury prevention interventions have focused on women and girls. ${ }^{2,3,23,37,39,50}$

The rate of injuries in soccer depends on several factors: age, level of competition, position on the field, environmental setting, location of injury, time of injury, and sex. These injuries most commonly involve the lower extremities and typically consist of mild to moderate

*** References 1, 4-8, 13, 15, 17, 22, 36, 41, 43.

$\dagger \dagger$ References 12, 14, 16, 18, 22, 29, 30, 33, 34, 39-41, 44, 48, 50-52. 
sprains, strains, or contusions. ${ }^{27,36,56}$ In studies analyzing the injury rates of professional male soccer athletes, researchers have found an overall injury rate ranging from 6.2 to 13.2 injuries per 1000 athlete-exposures (AEs). ${ }^{7,22,43}$ In a collegiate analysis of male soccer injuries, the game injury rate was 21.92 per 1000 AEs in Division I and 20.43 per 1000 AEs in Division II; the practice injury rate was 4.60 per 1000 AEs in Division I and 4.40 per 1000 AEs in Division II. ${ }^{1}$

The Fédération Internationale de Football Association (FIFA) and its Medical Assessment and Research Centre (F-MARC) developed injury prevention programs such as the "11" and the "FIFA 11+" in an effort to improve strength and reduce the incidence of all injuries incurred as a result of soccer participation. ${ }^{10,52,55}$ These programs have been evaluated in both sexes; in recreational, amateur, and semiprofessional soccer; and in court-based sports (basketball in the study by Longo et al ${ }^{38}$ ). ${ }^{31,49,52,55,58}$ To address the compliance issue and perhaps some of the inadequacies of the therapeutic exercises initially selected for the " 11 " protocol, an international group of researchers reconvened and restructured the " 11 " program and developed a dynamic warm-up program that addressed the major deficiencies that were deemed to be ubiquitous to soccer athletes, renamed as the "FIFA 11+" program. The program effectively reduced soccer-related injuries in multiple studies and has been shown to optimally, from a physiological perspective, prepare the athlete for competition. $9,31,35,49,58$ The program has also demonstrated the ability to improve muscular strength that may be deemed integral to injury prevention. ${ }^{18,45,50}$

The aim of this research study was to describe the use of the FIFA 11+ program in competitive male soccer athletes in the collegiate setting. We hypothesized that the teams who participated in the FIFA 11+ intervention program would have a lower rate of injuries and incur a reduction in time loss due to injury in comparison to the control group.

\section{Methods}

\section{Study Design and Recruitment}

A prospective, cluster randomized controlled trial was conducted in NCAA Division I and

Division II men's soccer teams. Every athletic director, head soccer coach, and head athletic trainer from each institution with a men's college Division I or II soccer program $(\mathrm{N}=396)$ was contacted via a formal letter, an email that reiterated the written letter, and a direct telephone call. The letter and email included a hyperlink for video clips that featured former and current prominent US soccer players and a coach who discussed the nature and importance of injury prevention in the sport of soccer (http://vimeo.com/25708967 and http://vimeo.com/25708960). The inclusion criteria included current student athletes who were participating in an NCAA Division I or Division II member institution and, to avoid participant contamination, who had not participated in an injury prevention program in the past 4 competitive seasons. Sixty-five institutions consented to participate; participants from each institution ranged in age from 18 to 25 years. Human ethics internal review board approval was obtained through Quorum Review IRB. Before randomization, player consent was obtained, and a document of coaching comprehension was signed by each institution to ensure that there was a thorough understanding of the expectations of study participation. The randomization of each club was conducted utilizing a random number generator once 
every enrolled team had been identified. Upon randomization of the enrolled institutions, the intervention group (IG) received an instructional FIFA 11+ DVD, an injury prevention manual, and explanatory placards describing the FIFA 11+ intervention at length (www.fmarc.com/11plus). The control group (CG) received the identical study materials as the IG at the end of the data collection process.

An Internet-based injury surveillance system (HealtheAthlete) was utilized by every enrolled institution. Every AE, incurred injury, utilization of the FIFA 11+ program, and compliance data were entered weekly by the team's certified athletic trainer (ATC) and verified by the research staff. Sixty-one institutions completed the study during the fall 2012 season (August-December): 34 control institutions ( $\mathrm{n}=850$ athletes) and 27 intervention institutions ( $n=675$ athletes) (Figure 1). Demographic information, including age, position played, and leg dominance, was also collected. Upon the completion of the season, the injury data entry was confirmed by each ATC and batched with his or her individual institution's data collection system for accuracy and thoroughness. During the course of the season, the individual compliance of the program was monitored by the research team weekly. In the event that compliance within the IG was deemed less than optimal, a member of the research team contacted the team to encourage improvements in compliance.

\section{Intervention Program}

The FIFA $11+$ is an injury prevention program designed as an alternative warm-up program to address lower extremity injuries incurred in the sport of soccer for athletes older than 14 years. ${ }^{10}$ It is a 20 -minute program that is utilized on the field without any additional or onerous equipment necessary, and it consists of 15 exercises divided into 3 separate components: running exercises ( 8 minutes) that encompass cutting, change of direction, decelerating, and proper landing techniques; strength, plyometric, and balance exercises (10 minutes) that focus on core strength, eccentric control, and proprioception; and lastly, running exercises ( 2 minutes) to conclude the warm-up and prepare the athlete for athletic participation. There are 3 levels for each specific exercise (levels 1-3) that increase the difficulty for each respective exercise. This allows for both individual and team progression throughout the course of the competitive season ${ }^{26}$ (http://f-marc.com/11plus/home/) (see Appendix 1, available in the online version of this article at http://ajsm.sagepub.com/ supplemental). In this specific study, the FIFA 11+ program served as the intervention program over the course of 1 competitive collegiate soccer season. The warm-up was suggested to be utilized 3 times per week for the duration of the season. In comparison, typical soccer warm-up programs are quite heterogeneous and typically encompass running exercises, static and/or dynamic stretching, movements involving change of direction, and short passing. They typically average from 5 to 45 minutes in duration. The average warmup program does not typically emphasize qualitative movement. ${ }^{9,10}$

\section{Exposure, Injury Data Entry, and Compliance}

Upon consenting to participate in the study, each team provided a roster to be entered into the HealtheAthlete injury surveillance system. The surveillance system was a web-based system that was a data-secured, Health Insurance Portability and Accountability Act (HIPAA)-compliant site that utilized the Verisign secure second-factor logon feature. The 
injury and exposure data for each player on the roster were entered by the team's ATC. All injuries were entered weekly by the ATC and were verified and crosshatched with his or her institutional injury surveillance system at the end of the competitive season. The ATC indicated on which days the FIFA 11+ program was completed and which athletes participated in the training. The NCAA calendar was entered for each respective club to delineate the full soccer schedule, which commenced in August 2012 and ended in December 2012 (contingent upon the success of the institution in the NCAA playoff tournament). No unique identifiers that would reveal the identity of the team or the athlete were visible to any of the research staff.

The operational definition for an $\mathrm{AE}$ was participation in any team practice or game during preseason or in-season. We decided to use AEs over hours of playing time secondary to the NCAA substitution rules. ${ }^{47}$ An injury was defined as any physical complaint sustained by a player that resulted from a football match or football training, irrespective of the need for medical attention or time loss from football. An injury resulting in a player receiving medical attention was referred to as a "medical attention" injury and an injury that resulted in a player being unable to take full part in future football training or match play as a "timeloss" injury. 27

\section{Statistical and Data Analyses}

All statistical analyses were conducted utilizing SPSS for Windows version 22. Descriptive and inferential tests were used to compare the CG and IG, including $t$ tests, $\chi^{2}$ tests, and generalized linear regression models, with a logit link function and Poisson distribution for count data. Two generalized linear regression models (Biostatistics Core Facility, University of Delaware) were used to test if there was a significant difference in the number of days missed because of injuries between the IG and CG and, secondly, to test if the number of days missed because of injuries was different for athletes who had used the FIFA 11+ on the day of the injury. All injuries that occurred throughout the fall 2012 soccer season were analyzed by location, duration, and turf type (grass vs artificial turf).

\section{Results}

The CG consisted of 850 athletes (56\%) in 34 teams (56\%) who had 44,212 (56\%) AEs (games: 13,624; practices: 30,588). The IG consisted of 675 athletes (44\%) in 27 teams (44\%) who had 35,226 (44\%) AEs (games: 10,935; practices: 24,291). The CG had a significantly higher number of injuries per team (mean $\pm \mathrm{SD}, 19.56 \pm 11.01)$ compared with that of the IG (mean $\pm \mathrm{SD}, 10.56 \pm 3.64)(t(59)=4.07 ; P<.001$; Cohen $d=1.16)$. The number of participants who needed to be exposed to the intervention to reduce 1 injury in the IG (number needed to treat [NNT]) was 3 . The mean utilization of the FIFA $11+$ in the IG was $32.78 \pm 12.13$ doses over the course of the season. There was no significant difference between the age of the injured athletes (IG: $20.40 \pm 1.66$ years; CG: $20.68 \pm 1.46$ years), nor was there a difference in the number of injured athletes based on player position (Table 1).

When the data were stratified by division of play (I or II) and for game and practice, the Division I CG had a significantly higher number of game injuries $(n=200$ [56.3\%]; mean \pm 
$\mathrm{SD}, 12.5 \pm 5.51$; incidence rate $[\mathrm{IR}], 29.36)$ compared with Division I IG game injuries ( $\mathrm{n}=$ 122 [61.6\%]; mean $\pm \mathrm{SD}, 6.13 \pm 2.47$; IR, 18.83) $(P=.000038)$ (see Appendix 2, available online). There was a similar outcome for Division I and Division II practices. There was a significant difference between the Division I CG practice injuries $(n=155$ [43.7\%]; mean \pm $\mathrm{SD}, 9.69 \pm 7.6$; IR, 10.13) compared with Division I IG practice injuries ( $\mathrm{n}=76$ [38.4\%]; mean $\pm \mathrm{SD}, 3.44 \pm 1.86$; IR, 5.146) $(P=.0027)$. There was also a significant difference between the Division II CG practice injuries $(\mathrm{n}=118$ [38.1\%]; mean $\pm \mathrm{SD}, 6.56 \pm 4.42$; IR, 7.72) compared with Division II IG practice injuries ( $\mathrm{n}=24$ [27.6\%]; mean $\pm \mathrm{SD}, 3.14$ \pm 1.57 ; IR, 2.36) $(P=.0457)$. There was no significant difference found between the $\mathrm{CG}$ and IG in Division II game injuries (see Appendix 2).

The injury rates were significantly lower in the IG when stratified for type of injury as well (Table 2 and Figure 2). The highest number of reported injuries in both the CG and IG were ankle injuries. The CG reported 115 ankle injuries, accounting for $17.3 \%$ of the total CG injuries (IR, 2.601), compared with 59 ankle injuries in the IG (20.7\% of total injuries; IR, 1.675; rate ratio [RR], 0.65 [95\% CI, 0.48-0.87]). Knee-related injuries were the second highest reported injury for both groups. The CG reported 102 total knee injuries (15.3\%; IR, 2.307) compared with 34 in the IG (11.9\% of total injuries; IR, 0.965; RR, 0.42 [95\% CI, $0.29-0.61]$; NNT = 14). When the data were stratified for type of knee injury, there were 16 ACL injuries reported in the CG (2.4\%; IR, 0.362) and 3 ACL injuries in the IG (1.1\%; IR, 0.085), accounting for a 4.25-fold reduction in the likelihood of incurring an ACL injury (RR, 0.236 [95\% CI, 0.193-0.93]; NNT $=70 ; P<.001$ ). A similar trend was seen with respect to acute hamstring injuries. There were 55 hamstring injuries reported in the CG (8.3\%; IR, 1.244) compared with 16 in the IG (5.6\%; IR, 0.454), accounting for a 2.74-fold reduction in the likelihood of incurring a hamstring injury (RR, 0.37 [95\% CI, 0.21-0.63]; $\mathrm{NNT}=24 ; P<.001)$.

A Poisson regression was used to compare the total number of days missed between groups, IG versus CG, and for field types (grass vs turf) because the number of days missed is a count variable and normality was violated for both groups. The overall model was significant (likelihood ratio $[\mathrm{LR}] \chi^{2}(2)=263.06 ; P<.001$ ). There was a significantly higher number of days missed in the CG (mean $\pm \mathrm{SD}, 13.20 \pm 26.6$ days) than in the IG (mean \pm $\mathrm{SD}, 10.08 \pm 14.68$ days) (Wald $\chi^{2}(2)=7.35 ; b=0.34 ; \mathrm{SE}=0.12 ; P=.007$ ); for each day missed in the IG, 1.4 days were missed in the CG (odds ratio [OR], 1.40). The total number of days missed because of injuries was 8790 in the CG compared with 2944 in the IG. There was no difference in either group for days missed based on field type (Wald $\chi^{2}(2)=0.91 ; b=$ $0.13 ; \mathrm{SE}=0.14 ; \mathrm{OR}, 1.15 ; P=.341$ ).

A second Poisson regression was used for those who were in the IG to compare the number of days missed if the injury occurred on a day when the intervention was used. The model was significant $\left(\operatorname{LR} \chi^{2}(2)=6.02 ; P<.049\right)$. There was a significantly higher number of days missed when the intervention was not used on the day of injury (mean \pm SD, $10.65 \pm 15.35$ days) than when it was used (mean $\pm \mathrm{SD}, 6.56 \pm 10.44$ days) (Wald $\chi^{2}(1)=4.26 ; b=4.08$; $\mathrm{SE}=1.98 ; P=.039$ ). There was no difference in the number of days missed in the IG based on field type (Wald $\chi^{2}(1)=0.90 ; b=2.10 ; \mathrm{SE}=2.21 ; P=.343$ ). 


\section{Compliance}

Compliance of the intervention was analyzed and stratified by utilization consistency. Compliance was determined to be low (LC: 1-19 doses/season), moderate (MC: 20-39 doses/season), or high (HC: $>40$ doses/season). The mean $( \pm \mathrm{SD})$ utilization per team was $30.47 \pm 12.16$ FIFA $11+$ sessions. There were 54 injuries in 4 teams reported in the LC group (mean, 13.5 doses/season [range, 10-19 doses/season]; IR, 10.353 \pm 2.21 ), 156 injuries in 14 teams in the MC group (mean, 11.14 doses/season [range, 21-39 doses/ season]; IR, $8.545 \pm 2.46$ ), and 75 injuries in 9 teams in the HC group (mean, 8.33 doses/ season [range, 40-64 doses/season]; IR, $6.39 \pm 2.71$ ). There was a statistically significant difference reached, and an inverse relationship between the utilization compliance of the FIFA $11+$ and the injury rate was identified $(P=.034)$. The greater the team compliance to the program, the lower the injury rate within that respective cohort (Figure 3).

\section{Discussion}

The FIFA 11+ was designed as a concise and comprehensive warm-up program to address lower extremity injuries associated with the sport of soccer. In this study, the principal finding in this randomized controlled trial was that, by virtue of utilizing the FIFA 11+, there was an overall reduction of injuries in the IG by $46.1 \%$, demonstrating the decreased likelihood of an athlete in the IG being injured (RR, 0.54 [95\% CI, 0.49-0.59]; $P<.0001$; $\mathrm{NNT}=2.64)$. This is consistent with other studies that have elucidated the efficacy of the $11+$ in similar populations. ${ }^{31,49,52,55}$ There was a statistically significant reduction in injuries with respect to individual injuries (IR, 15.04/1000 AEs [CG] vs 8.09/1000 AEs [IG]; $P<.001$ ) and in relation to injuries per team (mean injuries/team: 19.56 [CG] vs 10.56 [IG]; $P<.001)$. This reinforces the findings of other authors, elucidating the protective benefit of the FIFA $11 \pm$ program for both men and women.

When the data were analyzed for division of play (Division I or II), there were significant reductions in the IG for Division I game (IR, 29.36 [CG] vs 18.83 [IG]; $P=.000038$ ) and practice injuries (IR, $10.13[\mathrm{CG}]$ vs $5.146[\mathrm{IG}] ; P=.0027$ ) and Division II practice injuries. There was no statistical difference in Division II game injuries, but a trend for injury reduction in this cohort was apparent $(P=.3762)$ (see Appendix 2). This injury distribution with respect to level of play and game versus practice injury is consistent with the existing literature. ${ }^{1,21,23,31}$

The FIFA $11+$ program was first tested in female soccer players in Norway. Soligard et al ${ }^{52}$ conducted a cluster randomized controlled trial in 125 female youth soccer clubs in Norway (aged 13-17 years): 65 teams in the IG $(n=1055)$ and 60 teams in the CG $(n=837)$ followed the protocol for 1 season ( 8 months). During the season, 264 players had relevant injuries: 121 players in the IG and 143 in the CG (RR, 0.71 [95\% CI, 0.49-1.03]). In the IG, there was a significantly lower risk of injuries overall (RR, 0.68 [95\% CI, 0.48-0.98]), overuse injuries (RR, 0.47 [95\% CI, 0.26-0.85]), and severe injuries (RR, 0.55 [95\% CI, $0.36-0.83])$. This indicates that a structured warm-up program can prevent injuries in young female soccer players. 
In a small cohort study conducted of men's collegiate soccer in the US, Grooms et al ${ }^{31}$ utilized the FIFA 11+ intervention for 1 Division III soccer team ( $N=41$; aged 18-25 years). The first season served as the referent season, and the second season served as the intervention assessment. The injury rate in the referent season was 8.1 injuries per 1000 AEs with 291 days lost and 2.2 injuries per 1000 AEs and 52 days lost in the intervention assessment season. The intervention assessment season demonstrated reductions in the relative risk of lower extremity injuries of $72 \%$ (RR, 0.28 [95\% CI, 0.09-0.85]) and time lost to lower extremity injuries $(P<.01)$. Despite the small sample size, there was a statistically significant reduction in the injury rate and time lost to injury. The researchers noted excellent compliance and adherence to the program and benefited from direct oversight from an ATC at every exposure.

A recent study investigated the efficacy of the FIFA 11+ in a male soccer cohort in the African Laos Junior League. Owoeye et $\mathrm{al}^{49}$ utilized the FIFA $11+$ intervention in a cluster randomized trial in 20 teams $(\mathrm{N}=416$ players: intervention $=212$ players, control $=204$ players) over the course of 6 months. In total, 130 injuries were recorded, affecting 104 $(25 \%)$ of the 416 players. The FIFA $11+$ program significantly reduced the overall rate of injuries in the intervention group by $41 \%(\mathrm{RR}, 0.59$ [95\% CI, 0.40-0.86]; $P=.006)$ and all lower extremity injuries by $48 \%$ (RR, 0.52 [95\% CI, 0.34-0.82]; $P=.004)$. However, the rate of injury reduction based on secondary outcomes mostly did not reach the level of statistical significance.

The FIFA 11+ program has been shown to be an efficient means of achieving optimal physiological readiness for sport. ${ }^{9}, 35$ The program has also been shown to increase muscle activation in the rectus abdominis, gluteus medius, and gluteus minimus immediately after completing the program, corroborating its effect on core activation. ${ }^{45}$ Daneshjoo et al ${ }^{18}$ analyzed the effect of the FIFA 11+ on knee strength in male competitive soccer players. Quadriceps and hamstring strength was assessed after 24 sessions of utilizing the FIFA 11+ program in $\mathrm{U}-21$ male soccer players $(\mathrm{N}=36)$; concentric quadriceps peak torque increased by $27.7 \%$ at $300 \mathrm{deg} / \mathrm{s}$ in the dominant leg $(P<.05)$, and concentric hamstring peak torque increased by $22 \%, 21.4 \%$, and $22.1 \%$ at 60,180 , and $300 \mathrm{deg} / \mathrm{s}$, respectively, in the dominant leg and by $22.3 \%$ and $15.7 \%$ at 60 and $180 \mathrm{deg} / \mathrm{s}$, respectively, in the nondominant leg compared with the control group.

The results in the aforementioned articles suggest that consistent utilization of a neuromuscular training program, such as the FIFA 11+, may impart a protective benefit to the soccer athlete by achieving an optimal state of physiological preparedness for soccer competition and sufficient biomechanical training to offset the risk of injuries associated with soccer participation.

\section{Evolution of the Program}

Steffen et al ${ }^{55}$ attempted to reduce the incidence of ACL injuries by using a set of exercises known as "The 11." It was a cluster randomized controlled trial to test the efficacy of the " 11 " on the injury risk in female soccer players (IA, 59 teams; $n=1091$ ) compared with a control group (CA, 54 teams; $\mathrm{n}=1001)$. A total of 396 players (20\%) sustained 483 injuries. There was no difference in the overall injury rate between the IA (3.6 injuries/1000 athlete- 
hours [95\% CI, 3.2-4.1]) and CA (3.7 injuries/1000 athlete-hours [95\% CI, 3.2-4.1]; RR, 1.0 [95\% CI, 0.8-1.2]; $P=.94$ ), nor was there a difference in the IR for type of injury. The training program was utilized during $60 \%$ of the soccer training sessions in the first half of the season, but only 14 of 58 intervention teams completed more than 20 prevention training sessions throughout the course of the season. The researchers noted no effect of the injury prevention program on the injury rate perhaps because of the exercises not being specific enough to address the biomechanical deficiencies present in this population. Furthermore, the low compliance rates among the intervention teams could have negatively affected the prevention benefit. However, a study analyzing the efficacy of "The 11" in adult male amateur players ( $\mathrm{N}=23$ teams; 11 intervention teams [223 players] and 12 control teams [233 players]) showed a significant difference in the incidence of knee injuries but not in overall injuries (9.6 injuries/1000 athlete-hours [95\% CI, 8.4-11.0] for the intervention and 9.7 injuries/1000 athlete-hours [95\% CI, 8.5-11.1] for the control), despite having good compliance ( $73 \%$ compliance rate for teams and $71 \%$ for players). 58 "The 11 " program was subsequently revamped into "The 11+" to address the inadequacies in the former program's components.

\section{Compliance}

A variable worthy of discussion, which may positively or negatively affect the efficacy of a neuromuscular injury prevention intervention, is the role of compliance. It has been demonstrated that compliance is inversely correlated with the injury rate; the more regularly the neuromuscular training programs are implemented, the lower the reported injury rate. ${ }^{52}$ High adherence to injury prevention programs, specifically the FIFA $11+$, resulted in lower injury rates in a Canadian youth female soccer cohort (incidence rate ratio, 0.28 [95\% CI, $0.10-0.79]) .{ }^{53}$ In contrast, when compliance and adherence to a program are diminished, the propensity of the prevention program to be effective is limited as well. ${ }^{55}$ In this current study, there was an inverse relationship between the injury rate and compliance; as compliance increased, injury rates subsequently decreased with statistical significance $(P=$. 034) (Figure 3). It is critical to effectively communicate the importance of the regularly scheduled implementation of programs such as the FIFA $11+$ to fully impart their benefits to the soccer community at large.

\section{Program Dissemination}

The NCAA FIFA 11+ program was delivered without direct contact to the ATC at each respective institution because of the wide geographic expanse of the randomized groups. The researchers relied solely on video, DVD, and printed materials to ensure proper implementation of the program with a proper biomechanical technique. The fact that the ATC was the point person for FIFA 11+ delivery as well as injury collection is a strength of the study, as ATCs are highly qualified and well-educated members of the multidisciplinary medical team. The subject of program delivery has been the source of debate in the literature. ${ }^{10,29,51,52,54,55}$ Steffen et $\mathrm{al}^{53}$ examined the effect of different delivery methods on compliance and injury rates in youth soccer. Teams that had supervision and had access to a coach-focused workshop demonstrated greater adherence to the FIFA 11+ program compared with the control teams, who only had access to the educational website $(85.6 \%$ and $81.3 \%$, respectively; control, $73.5 \%$ ). Players with high adherence to the FIFA 11+ 
program had a 57\% lower injury risk, but this was not statistically significant. This research demonstrates that despite financial and geographic limitations associated with the multicultural and global appeal of the sport of soccer, the factor that remains critical to optimal injury prevention outcomes is imploring coaching and training staff to regularly utilize such programs on a weekly basis.

Another factor to consider with implementation is the timing of the intervention during the course of training. The PEP program and the FIFA 11+, among others, have been designed as dynamic warm-up programs to be utilized before training. ${ }^{10,40,52}$ The rationale behind this method of delivery is to increase compliance, as warm-ups are consistently utilized in the sport of soccer, and to neuromuscularly prepare the athlete for training in a nonfatigued state. When a neuromuscular training program is delivered, it should be performed with a proper biomechanical technique. If the exercises are performed in a fatigued state, or with a poor or inconsistent biomechanical technique, a pathokinematic motor pattern may be neuromuscularly reinforced. A study that utilized an injury prevention program after training, in a fatigued state, and devoid of a strength element was largely unsuccessful in reducing the rate of ACL injuries across 3 sports. ${ }^{51}$

\section{Limitations}

There are several factors to consider with respect to the methodological limitations of the study. The study was only conducted over the course of a single NCAA competitive season (August-December 2012). The average Division I and II teams have 18 and 18 games and 51 and 52 practices, respectively, throughout the course of the season. ${ }^{1,19}$ Because of the truncated nature of the collegiate season, it is often challenging to impart the full neuromuscular benefit of such a program because of the short duration of the season compared with domestic professional and European leagues (9- to 10-month season). In addition, training for the study was accomplished remotely via a website (www.f-marc.com/ 11plus), an educational video clip (Vimeo), an instructional DVD, a manual, and a PDF poster detailing the elements and progression of the FIFA 11+. There was no direct contact or training with each individual institution or the team ATC because of the wide geographical expanse of the study population. However, the ATC was responsible for initiating each session at his or her respective institution and for entering the injury data in a medical database. The ATC served as a highly qualified medical professional who vastly improved the quality of the data entered into the HealtheAthlete secure system. ${ }^{19}$ In a recent study, various FIFA 11+ implementation strategies were investigated in a cluster randomized controlled trial. The study compared (1) unsupervised, website-directed FIFA 11+ implementation with a comprehensive coach-focused workshop (2) with and (3) without regular supervision by a physical therapist. The researchers found that teams in the comprehensive and regular interventions demonstrated greater compliance, which was not statistically significant. Players with higher compliance to the program showed lower injury rates, which were not shown to be statistically significant either. ${ }^{54}$ However, this may speak to the overall effectiveness and generalizability of the program. In this current study, we found a statistically significant difference between compliance groups in relation to the injury rate. Even in the LC IG teams $(n=4$; range, 10-19 doses), the athletes demonstrated an injury rate significantly lower than that of the CG teams (IR, 10.353 \pm 2.21 [LC], 8.545 
\pm 2.46 [MC], $6.39 \pm 2.71[\mathrm{HC}]$ vs $15.04 \pm 11.01$ [control]; $P=.034$ ). In continents with extensive geographic expanse, such as North and South America, Africa, and Australia, researchers may often depend on the electronic dissemination of medical information and program implementation. Although the authors contend that direct contact with coaches and players is optimal, electronic educational dissemination has been shown to be effective and cost efficient. In spite of the anonymous delivery system utilized in this study, the program was initiated during the preseason portion of the season and continued throughout the duration of the season with significant reductions in injuries and time loss due to injury. The authors contend, from a public health perspective, that the ease and generalizability of the program and the ability to deliver and disseminate the injury prevention message meaningfully and effectively over a vast geographic area are strengths of the program.

\section{Future Directions}

There have been several research studies that have illuminated the protective benefit of utilizing the FIFA 11+ prevention program as a viable alternative to an existing warm-up protocol. There have been notable reductions in injury rates in both male and female soccer players, and time loss due to injury had been significantly reduced by virtue of utilizing the FIFA $11+$ program. To fully understand the biomechanical changes imparted by the FIFA $11+$ through the kinematic chain, a thorough biomechanical motion analysis before and after utilization among men and women in various age groups and levels of competition would be warranted and is being conducted at the present time.

\section{Conclusion}

The FIFA 11+ was shown to reduce injury rates and time loss due to injury in the competitive male collegiate soccer player in a statistically significant manner. The more consistently the program was utilized, the greater the injury prevention benefit imparted to the athlete. The benefits of sport participation are numerous and far outweigh the risks associated with such. However, the likelihood of incurring an injury by virtue of participating in soccer should not be underestimated. As clinicians, it is integral to our collective ethos to recognize the risks associated with sport and to profess the merits of prevention protocols that have been presented in the peer-reviewed literature. This information may successfully reduce the incidence of sport-related injuries in a meaningful way. As researchers, we will continue to set our sights higher to improve the quality and efficacy of the prevention programs available to the athletic community. We recognize and embrace the need for program compliance and further randomized controlled trials to elucidate the epidemiology, mechanism of injury(s), and ultimate reduction and prevention of sport-related injuries.

\section{Supplementary Material}

Refer to Web version on PubMed Central for supplementary material.

\section{Acknowledgments}

The researchers would like to thank all of the NCAA Division I and Division II certified athletic trainers, coaching staff, and players who participated in this study. They are incredibly appreciative of the time, dedication, and 
compliance of these participants to this important body of research. The authors also thank Conrad Von Grebel (Von Grebel Motion AG, Zurich, Switzerland) for his generous assistance in filming the video necessary for participant recruitment, and Dennis Granelli for his statistical assistance in the refinement of this manuscript.

source of funding: H.S.-G., B.M., O.A., and S.I., as affiliates of the Santa Monica Sports Medicine Foundation, received a grant from FIFA in the amount of $\$ 150,000$ to run this large study. A large proportion of the funding was utilized for the injury surveillance database (HealtheAthlete) and the honorariums provided to each athletic trainer at each National Collegiate Athletic Association institution to assist in data collection.

\section{References}

1. Agel J, Evans TA, Dick R. Descriptive epidemiology of collegiate men's soccer injuries: National Collegiate Athletic Association Injury Surveillance System, 1988-1989 through 2002-2003. J Athl Train. 2007; 42(2):270-277. [PubMed: 17710176]

2. Alentorn-Geli E, Mendiguchía J, Samuelsson K, et al. Prevention of anterior cruciate ligament injuries in sports, part I: systematic review of risk factors in male athletes. Knee Surg Sports Traumatol Arthrosc. 2014; 22(1):3-15. [PubMed: 24385003]

3. Alentorn-Geli E, Mendiguchía J, Samuelsson K, et al. Prevention of non-contact anterior cruciate ligament injuries in sports, part II: systematic review of the effectiveness of prevention programmes in male athletes. Knee Surg Sports Traumatol Arthrosc. 2014; 22(1):16-25. [PubMed: 24162718]

4. Arendt E, Dick R. Knee injury patterns among men and women in collegiate basketball and soccer: NCAA data and review of the literature. Am J Sports Med. 1995; 23(6):694-701. [PubMed: 8600737]

5. Azubuike OS, Okojie HO. Epidemiology of soccer injuries in Benin City, Nigeria. Br J Sports Med. 2009; 43(5):382-386. [PubMed: 18927169]

6. Bailey R, Erasmus L. Incidence of injuries among male soccer players in the first team of the University of the Free State in the Coca Cola League: 2007/2008 season. SA J Sports Med. 2009; 21(1):3-6.

7. Bengtsson H, Ekstrand J, Hägglund M. Muscle injury rates in professional football increase with fixture congestion: an 11-year follow-up of the UEFA Champions League injury study. Br J Sports Med. 2013; 47(12):743-747. [PubMed: 23851296]

8. Beynnon BD, Vacek PM, Newell MK, et al. The effects of level of competition, sport, and sex on the incidence of first-time noncontact anterior cruciate ligament injury. Am J Sports Med. 2014; 42(8): 1806-1812. [PubMed: 25016012]

9. Bizzini M, Impellizzeri FM, Dvorak J, et al. Physiological and performance responses to the "FIFA $11+"$ (part 1): is it an appropriate warm-up? J Sports Sci. 2013; 31(13):1481-1490. [PubMed: 23855725]

10. Bizzini M, Junge A, Dvorak J. Implementation of the FIFA 11+ football warm up program: how to approach and convince the football associations to invest in prevention. Br J Sports Med. 2013; 47(12):803-806. [PubMed: 23813485]

11. Blatter, S. FIFA's Injuries to Women Health and Fitness for the Female Football Player: A Guide for Players and Coaches. Zurich: Fédération Internationale de Football Association; 2007.

12. Bollars P, Claes S, Vanlommel L, Van Crombrugge K, Corten K, Bellemans J. The effectiveness of preventive programs in decreasing the risk of soccer injuries in Belgium: national trends over a decade. Am J Sports Med. 2014; 42(3):577-582. [PubMed: 24481826]

13. Brophy R, Silvers HJ, Gonzales T, Mandelbaum BR. Gender influences: the role of leg dominance in ACL injury among soccer players. Br J Sports Med. 2010; 44(10):694-697. [PubMed: 20542974]

14. Caraffa A, Cerulli G, Projetti M, Aisa G, Rizzo A. Prevention of anterior cruciate ligament injuries in soccer: a prospective controlled study of proprioceptive training. Knee Surg Sports Traumatol Arthrosc. 1996; 4(1):19-21. [PubMed: 8963746]

15. Centers for Disease Control and Prevention. Nonfatal sports- and recreation-related injuries treated in emergency departments: USA, July 2000-June 2001. MMWR. 2000; 51:736-740. 
16. Cerulli G, Benoit DL, Caraffa A, Ponteggia F. Proprioceptive training and prevention of anterior cruciate ligament injuries in soccer. J Orthop Sports Phys Ther. 2001; 31(11):655-660. [PubMed: 11720298]

17. Chandy TA, Grana WA. Secondary school athletic injury in boys and girls: a three year comparison. Phys Sportsmed. 1985; 13:106-111.

18. Daneshjoo A, Mokhtar AH, Rahnama N, Yusof A. The effects of injury prevention warm-up programmes on knee strength in male soccer players. Biol Sport. 2013; 30(4):281. [PubMed: 24795499]

19. Dick R, Agel J, Marshall SW. National Collegiate Athletic Association Injury Surveillance System commentaries: introduction and methods. J Athl Train. 2009; 42(2):173-182. [PubMed: 21714302]

20. Dvorak, J.; Junge, A. F-MARC Football Medicine Manual: 1994-2005. Zurich: Fédération Internationale de Football Association; 2005. p. 81-93.

21. Ekstrand J, Gillquist J, Liljedahl SO. Prevention of soccer injuries: supervision by doctor and physiotherapist. Am J Sports Med. 1983; 11(3):116-120. [PubMed: 6346912]

22. Ekstrand J, Hägglund M, Fuller CW. Comparison of injuries sustained on artificial turf and grass by male and female elite football players. Scand J Med Sci Sports. 2010; 21(6):824-832. [PubMed: 20456680]

23. Engebretsen AH, Myklebust G, Holme I, Engebretsen L, Bahr R. Prevention of injuries among male soccer players: a prospective, randomized intervention study targeting players with previous injuries or reduced function. Am J Sports Med. 2008; 36(6):1052-1060. [PubMed: 18390492]

24. Faude O, Junge A, Kindermann W, Dvorak J. Injuries in female soccer players: a prospective study in the German national league. Am J Sports Med. 2005; 33:1694-1700. [PubMed: 16093546]

25. Fédération Internationale de Football Association. [Accessed October 25, 2014] 270 million people active in football. 2006. Available at: http://www.fifa.com/mm/document/fifafacts/bcoffsurv/ bigcount.statspackage_7024.pdf

26. Fédération Internationale de Football Association. [Accessed October 25, 2014] FIFA 11+ website. 2014. Available at: http://f-marc.com/11plus/home/

27. Fuller C, Ekstrand J, Junge A, et al. Consensus statement on injury definitions and data collection procedures for studies of injuries in football (soccer) injuries. Clin J Sport Med. 2006; 16(2):97106. [PubMed: 16603877]

28. Fuller C, Junge A, DeCelles J. "Football for Health": a football-based health-promotion programme for children in South Africa. A parallel cohort study. Br J Sports Med. 2010; 44:546554. [PubMed: 20547667]

29. Gilchrist J, Mandelbaum B, Melancon H, et al. A randomized controlled trial to prevent noncontact anterior cruciate ligament injury in female collegiate soccer players. Am J Sports Med. 2008; 36(8):1476-1483. [PubMed: 18658019]

30. Griffin LY, Albohm MJ, Arendt EA, et al. Understanding and preventing noncontact anterior cruciate ligament injuries: a review of the Hunt Valley II Meeting, January 2005. Am J Sports Med. 2006; 34(9):1512-1532. [PubMed: 16905673]

31. Grooms DR, Palmer T, Onate JA, Myer GD, Grindstaff T. Soccer-specific warm-up and lower extremity injury rates in collegiate male soccer players. J Athl Train. 2013; 48(6):782-789. [PubMed: 23848519]

32. Hägglund M, Waldén M, Ekstrand J. Lower reinjury rate with a coach-controlled rehabilitation program in amateur male soccer: a randomized controlled trial. Am J Sports Med. 2007; 35(9): 1433-1442. [PubMed: 17369558]

33. Hewett TE, Lindenfeld TN, Riccobene JV, Noyes FR. The effect of neuromuscular training on the incidence of knee injury in female athletes: a prospective study. Am J Sports Med. 1999; 27(6): 699-706. [PubMed: 10569353]

34. Hewett TE, Myer GD, Ford KR. Reducing knee and anterior cruciate ligament injuries among female athletes: a systematic review of neuromuscular training interventions. J Knee Surg. 2005; 18(1):82-88. [PubMed: 15742602] 
35. Impellizzeri FM, Bizzini M, Dvorak J, Pellegrini B, Schena F, Junge A. Physiological and performance responses to the FIFA 11+ (part 2): a randomised controlled trial on the training effects. J Sports Sci. 2013; 31(13):1491-502. [PubMed: 23855764]

36. Junge A, Dvorak J. Soccer injuries: a review on incidence and prevention. Sports Med. 2004; 34(13):929-938. [PubMed: 15487905]

37. Junge A, Rösch D, Peterson L, Graf-Baumann T, Dvorak J. Prevention of soccer injuries: a prospective intervention study in youth amateur players. Am J Sports Med. 2002; 30(5):652-659. [PubMed: 12238997]

38. Longo UG, Loppini M, Berton A, Marinozzi A, Maffulli N, Denaro V. The FIFA 11+ program is effective in preventing injuries in elite male basketball players: a cluster randomized controlled trial. Am J Sports Med. 2012; 40(5):996-1005. [PubMed: 22415208]

39. Malinzak RA, Colby SM, Kirkendall DT, Yu B, Garrett WE. A comparison of knee joint motion patterns between men and women in selected athletic tasks. Clin Biomech. 2001; 16(5):438-445.

40. Mandelbaum BR, Silvers HJ, Watanabe DS, et al. Effectiveness of a neuromuscular and proprioceptive training programme in preventing anterior cruciate ligament injuries in female athletes: 2-year follow-up. Am J Sports Med. 2005; 33:1003-1010. [PubMed: 15888716]

41. McLean SG, Huang X, Su A, Van Den Bogert AJ. Sagittal plane biomechanics cannot injure the ACL during sidestep cutting. Clin Biomech. 2004; 19(8):828-838.

42. MLSsoccer.com. [Accessed October 27, 2014] Expansion, refs, Cascadia: MLS Commissioner Don Garber covers it all in annual address. Feb 27. 2013 Available at: http://www.mlssoccer.com/ news/article/2013/02/27/expansion-refs-cascadia-commissioner-garber-covers-it-all-march-socceraddre

43. Morgan B, Oberlander M. An examination of injuries in Major Soccer League: the inaugural season. Am J Sports Med. 2001; 29:426-430. [PubMed: 11476380]

44. Myklebust G, Engebretsen L, Braekken IH, Skjølberg A, Olsen OE, Bahr R. Prevention of anterior cruciate ligament injuries in female team handball players: a prospective intervention study over three seasons. Clin J Sport Med. 2003; 13(2):71-78. [PubMed: 12629423]

45. Nakase J, Inaki A, Mochizuki T, et al. Whole body muscle activity during the FIFA 11+ program evaluated by positron emission tomography. PLoS One. 2013; 8(9):e73898. [PubMed: 24066082]

46. National Collegiate Athletic Association. [Accessed October 28, 2014] Estimated probability of competing in athletics beyond the high school interscholastic level. Available at: https:// www.ncaa.org/sites/default/files/Probability-of-going-pro-methodology_Update20123.pdf

47. National Collegiate Athletic Association. [Accessed October 29, 2014] Rules of the game: NCAA soccer officiating center circle. Available at: http://ncaasoccer.arbitersports.com/front/106254/Site/ Area/Rules-of-the-Game

48. Östenberg A, Roos H. Injury risk factors in female European football: a prospective study of 123 players during one season. Scand J Med Sci Sports. 2000; 10:279-285. [PubMed: 11001395]

49. Owoeye OB, Akinbo SR, Tella BA, Olawale OA. Efficacy of the FIFA 11+ warm-up programme in male youth football: a cluster randomised controlled trial. J Sports Sci Med. 2014; 13(2):321-328. [PubMed: 24790486]

50. Petersen J, Thorborg K, Nielsen MB, Budtz-Jørgensen E, Hölmich P. Preventive effect of eccentric training on acute hamstring injuries in men's soccer: a cluster-randomized controlled trial. Am J Sports Med. 2011; 39(11):2296-2303. [PubMed: 21825112]

51. Pfeiffer RP, Shea KG, Roberts D, et al. Lack of effect of a knee ligament injury prevention program on the incidence of noncontact anterior cruciate ligament injury. J Bone Joint Surg Am. 2006; 88:1769-1774. [PubMed: 16882900]

52. Soligard T, Myklebust G, Steffen K, et al. Comprehensive warm-up programme to prevent injuries in young female footballers: cluster randomised controlled trial. BMJ. 2008; 337:a2469. [PubMed: 19066253]

53. Steffen K, Emery CA, Romiti M, et al. High adherence to a neuromuscular injury prevention programme (FIFA 11+) improves functional balance and reduces injury risk in Canadian youth female football players: a cluster randomised trial. Br J Sports Med. 2013; 47(12):794-802. [PubMed: 23559666] 
54. Steffen K, Meeuwisse WH, Romiti M, et al. Evaluation of how different implementation strategies of an injury prevention programme (FIFA 11+) impact team adherence and injury risk in Canadian female youth football players: a cluster-randomised trial. Br J Sports Med. 2013; 47:480-487. [PubMed: 23486935]

55. Steffen K, Myklebust G, Olsen OE, Holme I, Bahr R. Preventing injuries in female youth football: a cluster-randomized controlled trial. Scand J Med Sci Sports. 2008; 18(5):605-614. [PubMed: 18208428]

56. Torg JS, Stilwell G, Rogers K. The effect of ambient temperature on the shoe-surface interface release coefficient. Am J Sports Med. 1996; 24(1):79-82. [PubMed: 8638758]

57. US Census Bureau. [Accessed October 28, 2014] Participation in selected sports activities. 2009. Available at: http://www.census.gov/compendia/statab/2012/tables/12s1249.pdf

58. van Beijsterveldt AM, van de Port IG, Krist MR, et al. Effectiveness of an injury prevention programme for adult male amateur soccer players: a cluster-randomised controlled trial. $\mathrm{Br} \mathrm{J}$ Sports Med. 2012; 46(16):1114-1118. [PubMed: 22878257] 

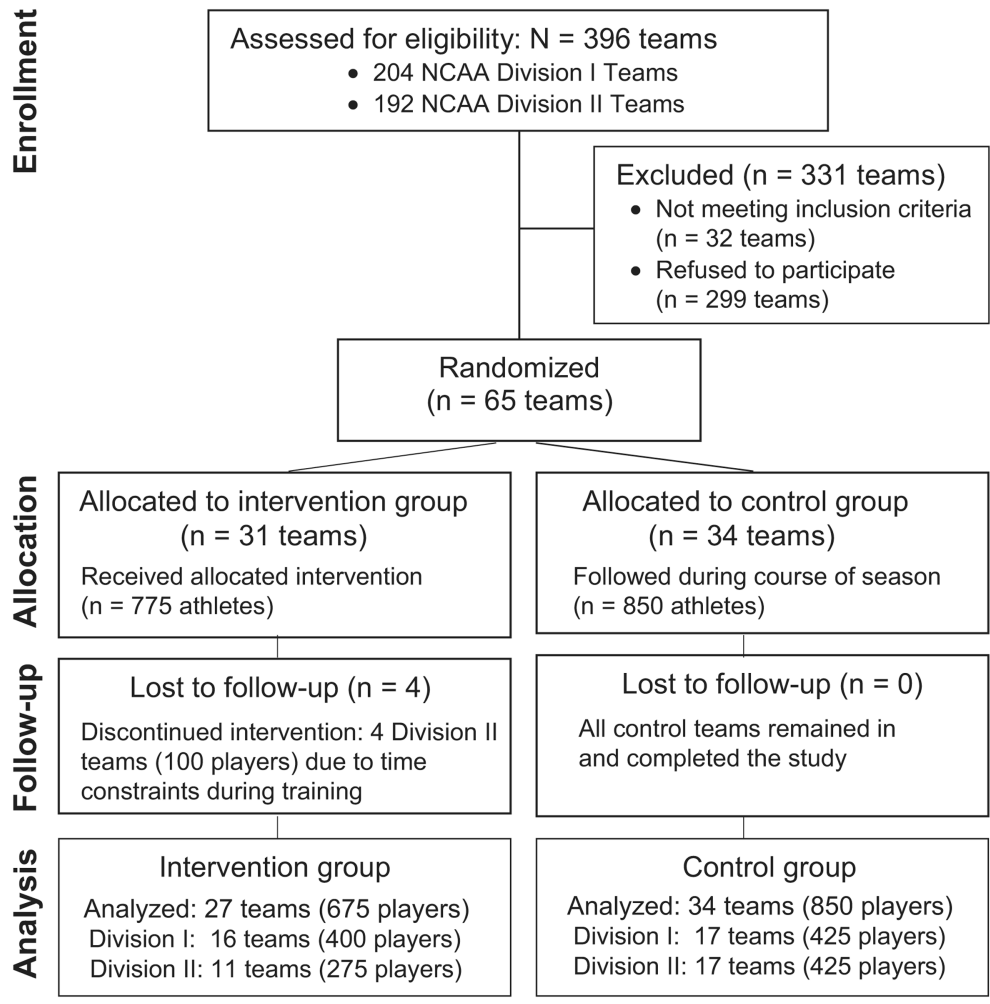

Figure 1.

Description of National Collegiate Athletic Association team randomization and study flow. 


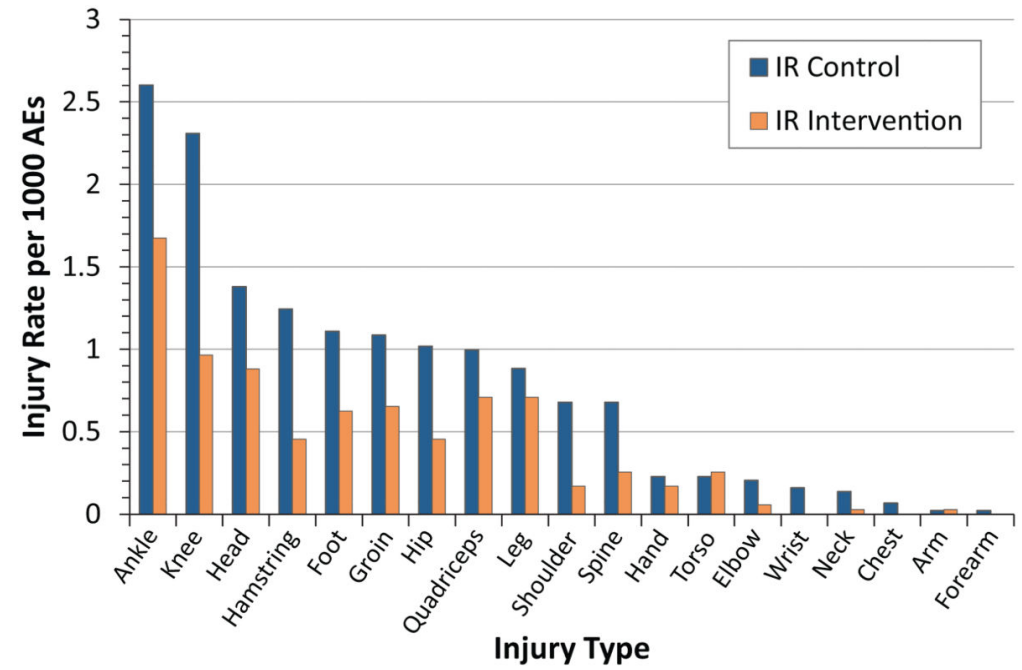

Figure 2.

Injury rate per 1000 athlete-exposures (AEs) classified by type and stratified by group. 


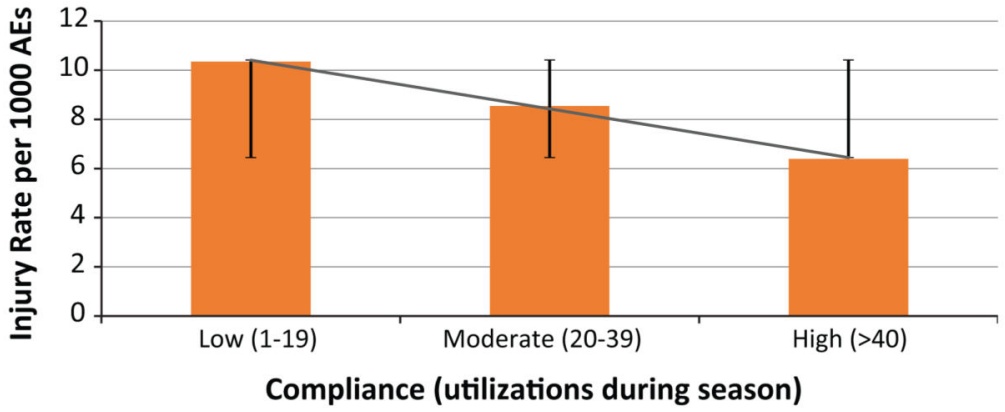

Figure 3.

Injury rates in relationship to compliance with the FIFA 11+ program. AE, athlete-exposure. 
Table 1

Player and Injury Characteristics for the Control and Intervention Groups ${ }^{a}$

\begin{tabular}{|c|c|c|}
\hline & Control Group $(n=34$ Teams $)$ & Intervention Group $(\mathrm{n}=27$ Teams $)$ \\
\hline No. of players & 850 & 675 \\
\hline Division I & 425 (17 teams) & 400 (16 teams) \\
\hline Division II & 425 (17 teams) & 275 (11 teams) \\
\hline Age, mean \pm SD, y & $20.68 \pm 1.46$ & $20.40 \pm 1.66$ \\
\hline \multicolumn{3}{|l|}{ No. of AEs } \\
\hline Total & 44,212 & 35,226 \\
\hline Games & 13,624 & 10,935 \\
\hline Practices & 30,588 & 24,291 \\
\hline \multicolumn{3}{|l|}{ Injuries by position, $\mathrm{n}(\%)$} \\
\hline Defender & $204(30.68)$ & $92(32.28)$ \\
\hline Forward & $132(19.85)$ & $67(23.51)$ \\
\hline Midfielder & $256(38.50)$ & $101(35.44)$ \\
\hline Goalkeeper & $73(10.98)$ & $25(8.77)$ \\
\hline Total injuries, $\mathrm{n}($ mean $\pm \mathrm{SD})$ & $665\left(19.56 \pm 11.01^{b}\right)$ & $285\left(10.56 \pm 3.64^{b}\right)$ \\
\hline Division I injuries, $\mathrm{n}$ (\% of total) & $355(53.4)$ & $198(69.5)$ \\
\hline Mean \pm SD & $22.19 \pm 12.0$ & $9.9 \pm 3.11$ \\
\hline Division II injuries, $\mathrm{n}$ (\% of total) & $310(46.6)$ & $87(30.5)$ \\
\hline Mean \pm SD & $17.22 \pm 10.03$ & $12.43 \pm 4.61$ \\
\hline Game injuries, n (\%) & $392(58.9)$ & $185(64.9)$ \\
\hline Mean \pm SD & $11.53 \pm 5.84^{b}$ & $6.85 \pm 3.17^{b}$ \\
\hline Practice injuries, n (\%) & $273(41.1)$ & $100(35.1)$ \\
\hline Mean \pm SD & $8.03 \pm 6.24^{b}$ & $3.70 \pm 2.13^{b}$ \\
\hline \multicolumn{3}{|l|}{ IR per 1000 AEs } \\
\hline Total & 15.04 & 8.09 \\
\hline Games & 28.77 & 16.92 \\
\hline Practices & 8.93 & 4.01 \\
\hline Days lost to injury $n$ (mean \pm SD) & $8790\left(13.20 \pm 26.6^{b}\right) ; \mathrm{SE}=1.09$ & $2944\left(10.08 \pm 14.68^{b}\right) ; \mathrm{SE}=0.96$ \\
\hline \multicolumn{3}{|l|}{ Time loss, $\mathrm{n}$ (\% of injuries) } \\
\hline No time loss & $201(30.2)$ & $104(36.5)$ \\
\hline $1-3 \mathrm{~d}$ & $126(18.9)$ & $31(10.9)$ \\
\hline $4-7 \mathrm{~d}$ & $94(14.1)$ & $43(15.1)$ \\
\hline $8-29 d$ & $164(24.7)$ & $81(28.4)$ \\
\hline $230 \mathrm{~d}$ & $80(12.0)$ & $26(9.1)$ \\
\hline
\end{tabular}

${ }^{a} \mathrm{AE}$, athlete-exposure; IR, incidence rate.

$b_{P<.001 .}$ 


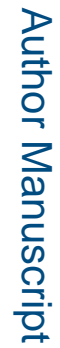

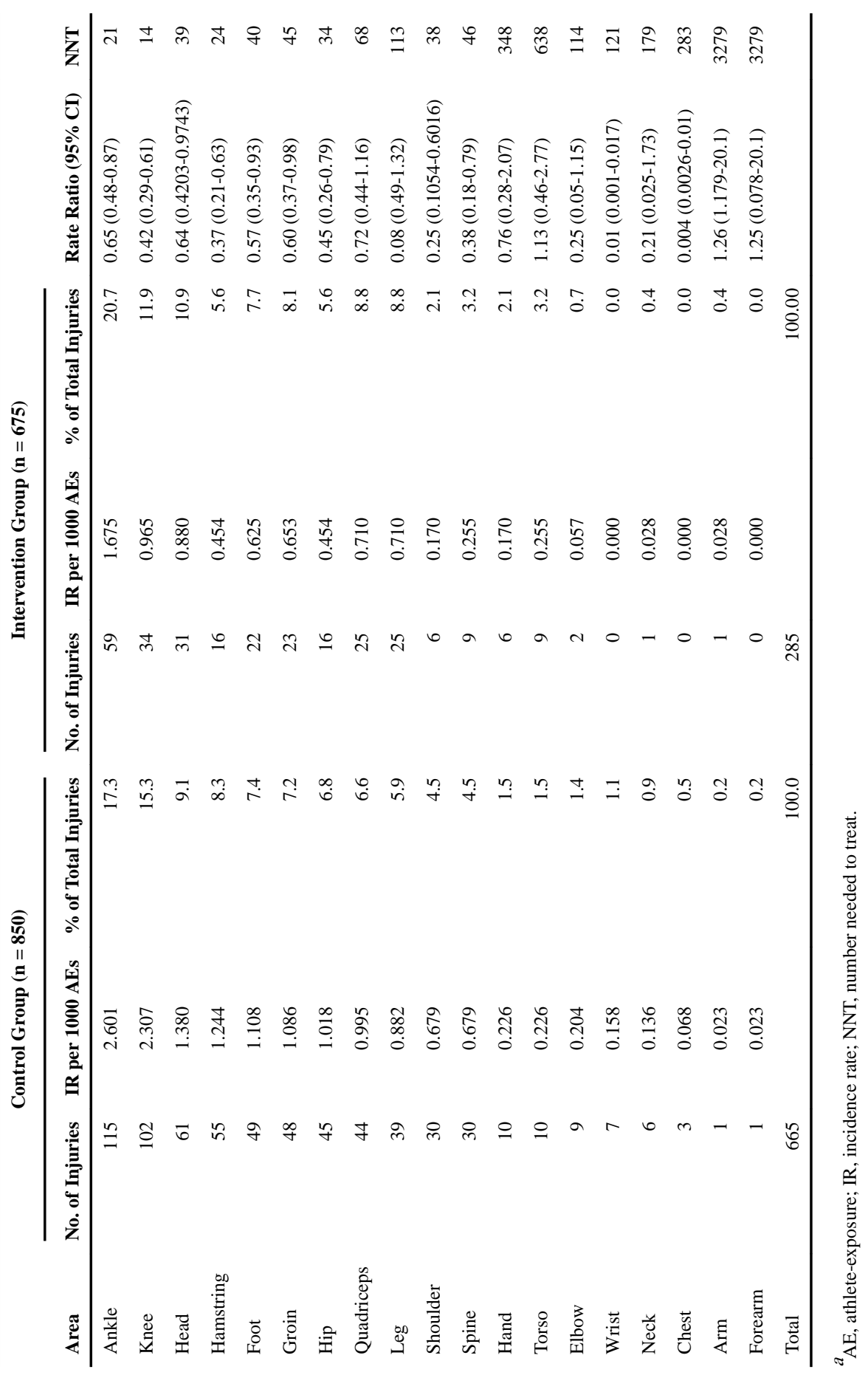

Am J Sports Med. Author manuscript; available in PMC 2016 April 21. 